\title{
Assessing the importance of predictors in unplanned hospital readmissions for chronic obstructive pulmonary disease
}

This article was published in the following Dove Press journal:

ClinicoEconomics and Outcomes Research

6 January 2015

Number of times this article has been viewed

Tzy-Chyi Yu'

Huanxue Zhou ${ }^{2}$

Kangho Suh'

Stephen Arcona'

'Novartis Pharmaceuticals Corporation, East Hanover, ${ }^{2} \mathrm{KMK}$ Consulting Inc., Florham Park, NJ, USA
Correspondence: Tzy-Chyi Yu Outcomes Research Methods and Analytics, Health Economics and Outcomes Research, Novartis Pharmaceuticals Corporation, One Health Plaza, East Hanover, NJ 07936-1080, USA

Email amanda.yu@novartis.com
Purpose: The all-cause readmission rate within 30 days of index admissions for chronic obstructive pulmonary disease (COPD) was approximately $21 \%$ in the United States in 2008 . This study aimed to examine patient and clinical characteristics predicting 30-day unplanned readmissions for an initial COPD hospitalization and to determine those predictors' importance.

Patients and methods: A retrospective study was conducted in patients with COPD-related hospitalizations using commercial claims data from 2010 to 2012. The primary outcome was all-cause unplanned readmission, with secondary outcomes being COPD as primary diagnosis and COPD as any diagnosis unplanned readmissions. Factors predicting unplanned readmissions encompassed demographic, pharmacy, and medical variables identified at baseline and during the index hospitalization. Dominance analysis was conducted to rank the predictors in terms of importance, defined as the contribution to change in model fit of a predictor by itself and in combination with other predictors.

Results: After applying the inclusion and exclusion criteria, 18,282 patients with index COPDrelated admissions were identified. Among them, the rates of unplanned readmissions with COPD as primary diagnosis, COPD as any diagnosis, and all-cause were $2.6 \%, 5.6 \%$, and $7.3 \%$, respectively. For each outcome, the readmission group was slightly older, had a greater COPD severity score, and required a longer length of stay. Moreover, the readmission group had larger proportions of patients with comorbidities, dyspnea/shortness of breath, intensive care unit stay, or ventilator use, compared to the non-readmission group. Dominance analysis revealed that the three most important predictors - heart failure/heart disease, anemia, and COPD severity score - accounted for $56 \%$ of the predicted variance in all-cause unplanned readmissions.

Conclusion: Overall, COPD severity score and heart failure/heart disease emerged as important factors in predicting 30-day unplanned readmissions across all three outcomes. Results from dominance analysis suggest looking beyond COPD-specific complications and focusing on comorbid conditions highly associated with COPD in order to lower all-cause unplanned readmissions.

Keywords: COPD, unplanned readmission, predictor importance, dominance analysis, administrative claims

\section{Introduction}

Reducing avoidable hospital readmissions is a quality-improvement and cost-containment strategy that is receiving much attention from both public and private payers in the United States. ${ }^{1}$ The US Centers for Medicare and Medicaid Services (CMS), Aetna, various Blue Cross and Blue Shield plans, WellPoint, and CIGNA, among other payers, employ active readmission reduction initiatives. ${ }^{2-6}$ One intervention demonstrated 
a $10 \%$ drop in readmission, resulting in savings of $\$ 3.8$ million by eliminating 400 readmissions and avoiding expected Medicare penalties. ${ }^{4}$

Approximately $17 \%$ of Medicare beneficiaries and 9\% of privately insured patients discharged from hospital are readmitted within 30 days, at an estimated annual cost of \$24 billion for Medicare and \$8 billion for private payers in 2011. ${ }^{7}$ Since 2012, the CMS has been penalizing hospitals for high all-cause readmission rates for certain conditions, including acute myocardial infarction (AMI), congestive heart failure (CHF), and pneumonia. ${ }^{8}$ The rationale for these penalties is premised upon the belief that unplanned readmission is an outcome of poor quality of inpatient care and/or discharge planning and that predictors of this outcome are in part under the control of hospitals and health systems. ${ }^{9}$ The three original all-cause readmission targets, namely AMI, CHF, and pneumonia, have led to $>2,000$ hospitals being penalized, with an estimated sum of $\$ 280$ million in penalties. $^{2}$

Under new CMS rules on the Hospital Readmission Reduction Program, to be implemented in October, 2014, 30-day all-cause unplanned readmission rates after an index hospitalization for an acute exacerbation of chronic obstructive pulmonary disease (COPD) will result in financial penalties for hospitals. ${ }^{8}$ COPD, including chronic bronchitis and emphysema, is estimated to affect approximately 27 million adults in the US, 12 million of whom were believed to be undiagnosed. ${ }^{10}$ Overall, the all-cause readmission rate within 30 days of index admission for COPD was approximately $21 \%$ in the US in 2008. ${ }^{11}$ COPD has been targeted by CMS, as it has the fourth highest number of readmission events within 30 days, with a $22 \%$ average readmission rate at an estimated annual cost of $\$ 0.9$ billion for Medicare in 2011. ${ }^{7}$ On average, readmission events $(\$ 8,400$ for COPD as primary diagnosis vs $\$ 11,100$ for all-cause in 2008) are more costly than initial hospitalizations $(\$ 7,100) .{ }^{11}$ Furthermore, since patients with COPD often have other comorbidities, it is costly to treat, with aggregate hospital costs of $\$ 5.7$ billion in $2011 .{ }^{12}$

Many studies, particularly in CHF, have generated multivariable regression models describing factors most important in predicting readmissions. ${ }^{13-15}$ These studies have been helpful in highlighting demographic and clinical variables potentially amenable to improvements in inpatient care, discharge planning, and post-discharge care coordination. COPD readmission risk has been informed also through a number of systematic literature reviews. ${ }^{16-18}$ These reviews highlighted certain factors, such as physical activity, patient self-management, smoking exposure, and respira- tory laboratory results (eg, the forced expiratory volume in 1 second), which were strongly associated with readmissions. A recent study modeled readmission risk through claims data and concluded readmission was related to comorbidities and pre-readmission health care use. ${ }^{19}$

Although prior research has described the relationship between hospital readmissions and a set of predictors using regression modeling, it often remains unclear to health care decision makers which predictors are most influential. This confusion is due to correlations between, and among the many predictors included in models. In this paper, an analytic technique called "dominance analysis" is used to supplement administrative claims-based regression modeling, in order to identify demographic and clinical characteristics of greatest predictive importance.

This study aimed 1) to build a predictive model of unplanned readmissions within 30 days of an initial COPD-caused hospitalization, and 2) to apply dominance analysis, in order to better determine the relative importance of predictors.

\section{Methods \\ Study population}

Patients were included in the study if they were at least 40 years of age and had a COPD-related hospitalization, as determined by a primary discharge diagnostic code related to COPD (The International Classification of Diseases, 9th Revision, Clinical Modification [ICD-9-CM] code: 491.21, 491.22, 491.8, 491.9, 492.8, 493.20, 493.21, 493.22, and 496). This likely ensured that a patient had a confirmed diagnosis of COPD, and that the reason for the hospital stay was primarily due to COPD-related complications.

A 3-year time frame was used, from January 1, 2009, to December 31, 2012, to ensure capture of a large sample size. The index hospitalization event was defined as the first qualified COPD-related hospitalization from January 1, 2010, to November 30, 2012. A 30-day period was assessed retrospectively from the identified index event, to ensure that a new hospitalization event had been identified and not a readmission event from a prior hospitalization occurring before the study time frame. If a subsequent COPD-related hospitalization had to be examined, the same method was used until a qualified COPD-related hospitalization was identified. If there was no qualified COPD-related hospitalization, the patient was dropped. In a situation where a patient had multiple hospitalization events within the study time frame, only the first event was used as the index event. Finally, patients were required to have continuous enrollment 
in medical and pharmacy benefits in the 12 months prior to the index admission date, as well as medical benefits for 30 days after the index discharge date.

Exclusion criteria included patients who passed away during the index admission and those who were discharged against medical advice. Patients who were subsequently transferred to another facility were also excluded, since it was not possible to determine whether or not the transfer was to an acute facility, which was not considered a readmission but rather planned care coordination.

\section{Data source}

The Truven Health MarketScan ${ }^{\circledR}$ Commercial Claims and Encounters (CCE) database was used for this analysis. This administrative claims database captures patient-level clinical utilization, expenditures, and enrollment across inpatient, outpatient, prescription drug, and carve-out services (specialist care contracted out from within the plan) from approximately 40 million patients per year from a selection of large employers, health plans, and government and public organizations in the US. ${ }^{20}$ The CCE includes data on active employees, early retirees, those receiving continuation coverage under the Consolidated Omnibus Budget Reconciliation Act, and their dependents insured by employer-sponsored plans. All study data were statistically certified as de-identified and were accessed in a manner compliant with the Health Insurance Portability and Accountability Act of 1996. Therefore, neither patient informed consent nor institutional review board approval was required.

\section{Outcome definitions}

The primary outcome of interest was all-cause unplanned readmission. Since planned readmissions are not considered signals of poor quality of care and/or discharge planning, we followed a claims-based algorithm from CMS in order to identify unplanned hospital readmissions after an episode of acute exacerbation COPD (see Grosso et $\mathrm{al}^{21}$ for the detailed algorithm and instructions). Two alternative definitions of readmissions were examined as well - COPD as primary readmission diagnosis, and COPD as any diagnosis (primary or secondary).

\section{Variable definitions}

Factors predicting unplanned readmissions were taken from a literature search, and encompassed demographic, pharmacy, and medical variables. ${ }^{19,22-30}$ They were then separated into the time period affected - at baseline or during the index hospitalization. Baseline characteristics were identified up to
12 months before index hospitalizations. Baseline variables consisted of age, sex, health plan type, geographic region, influenza vaccine use, adherence to COPD bronchodilator medication, depression, pulmonary vascular disease, chronic kidney disease (CKD), anemia, heart failure/heart disease, statin use, and COPD severity score. Variables attributed to index hospitalization included index hospitalization year, length of stay, winter season, dyspnea/shortness of breath, sepsis, pneumonia, intensive care unit (ICU) stay, ventilator use, and oxygen therapy.

Poor adherence to COPD bronchodilator medication (beta agonists, xanthine derivatives, steroids, anticholinergics, and combinations), were defined using a proportion-of-days-covered (PDC) value of $<0.8$ during the 365 days prior to the index event. The first prescription for any COPD medication was used to calculate PDC, without double counting multiple medications. PDC was defined as total days of supply divided by the patient's individual measurement period, which was the number of days from the first claims for a COPD prescription to the index event. ${ }^{31}$ As the index hospitalization may have been the first diagnosis of COPD for a patient, those who had a " 0 " PDC were categorized as no medication.

The COPD severity score was derived from claims-based pharmacotherapy and medical care use. ${ }^{29}$ The COPD severity score is a composite measure of 12 items, including hospitalization due to chronic bronchitis, oxygen therapy, acute exacerbations of chronic bronchitis, emphysema, spirometry tests, pulmonologist visits, anticholinergics, oral corticosteroids, inhaled corticosteroids, short-acting beta agonists, long-acting bronchodilators, and patient's age at mid-point of diagnosis year. The score ranges from zero to an upper bound determined by the inputs of the 12 items. Higher scores represent more severe states of COPD.

\section{Development of model and statistical analysis}

For comparison of baseline and index hospitalization characteristics, chi-square tests were performed for categorical variables and $t$-tests or Mann-Whitney $U$ tests for continuous variables. A logistic regression model was used to assess predictors of unplanned readmissions. To assess overall model fit, the model was internally validated, using a crossvalidation methodology. ${ }^{32}$ The full sample was randomly split into subsamples of $75 \%$ and $25 \%$ as the training and validation sets, respectively. The cross-validation process was repeated 1,000 times using different partitions. Average c-statistics and bootstrapped 95\% confidence intervals were 
reported. The SAS software version 9.2 (SAS Institute Inc., Cary, NC, USA) was used to conduct the analyses.

Afterward, to determine variables' importance, dominance analysis, as proposed by Azen and Traxel, ${ }^{33}$ was employed. As recommended by the authors, ${ }^{33}$ the McFadden $R^{2}$ statistic was used as the estimator of variance explained. The general dominance weight for a predictor was calculated from the McFadden $R^{2}$ statistic (see Azen and Traxel ${ }^{33}$ for details and instructions). Johnson and LeBreton defined relative importance as "the proportionate contribution each predictor makes to $R^{2}$, considering both its direct effect (eg, its correlation with the criterion [ $y$ or dependent variable]) and its effect when combined with the other variables in the regression equation." 34 Therefore, the general dominance weight from dominance analysis was normed or standardized to be out of $100 \%$ (ie, the general dominance weight of a variable divided by the sum of the general dominance weight of all variables) and reported as a standardized weight representing the proportionate contribution of a variable to variance explained.

Multiple regression alone does not provide complete information on the relative importance of predictors, especially when predictor variables in a model are correlated. In most cases when multiple predictors in a regression model are correlated with one another, there exists shared variance of the dependent variable among those correlated predictors. Standardized regression coefficients then cannot accurately identify contributions of individual predictors in model fit (see Johnson ${ }^{35}$ and Grömping ${ }^{36}$ for thorough discussions).

Dominance analysis addresses these issues by accounting for a variable's direct effect (when considered alone), its total effect (conditional on all other predictors), and its partial effect (conditional on subsets of predictors) in terms of its contribution to overall variance. ${ }^{37}$ As a result, dominance analysis is useful in health care decision making, since it considers all possible subset models in a pairwise fashion and provides one dominant and one dominated alternative, ${ }^{38}$ allowing the predictors to be ranked from "most important" to "least important". Among several predictor importance methods currently available, dominance analysis has been identified as one of the most useful approaches. ${ }^{34,36,39}$

\section{Results}

After applying the inclusion and exclusion criteria, 18,282 index patient admissions for COPD were identified. Figure 1 shows the patient selection flow. Follow-up yielded 1,332 (7.3\%) unplanned readmissions within 30 days for all-cause events, 1,022 (5.6\%) for COPD as any diagnosis, and
$480(2.6 \%)$ for COPD as primary diagnosis. Patients with unplanned readmissions for all-cause events were the primary focus of the analyses, so this group was referred to as the "readmission group" and their counterparts without unplanned readmissions were termed the "non-readmission group". Descriptive results for the readmission group versus the non-readmission group are shown in Table 1. Descriptive characteristics for the other two outcomes (unplanned readmissions with COPD as primary or with COPD as any diagnosis) are given in Tables S1 and S2.

The readmission group had an average age of 57.0 years and was primarily composed of women (59.5\%). Similarly, the non-readmission group had an average age of 56.5 years with women making up $62.7 \%$ of the group. The most frequently used health plan type for the readmitted group was fee-for-service $(84.8 \%)$ and for the non-readmitted group, also fee-for-service $(86.8 \%)$.

Adherence rates to COPD bronchodilator medication within the readmission group were $33.9 \%(n=452)$ adherent, 42.7\% $(n=569)$ non-adherent, and $23.3 \%(n=311)$ with no record of COPD medication. Interestingly, in the non-readmission group a lower percentage of patients were deemed adherent $(30.7 \%, \mathrm{n}=5,196)$ and non-adherent $(39.9 \%, \mathrm{n}=6,769)$, along with a higher percentage $(29.4 \%$, $\mathrm{n}=4,985$ ) of nonusers of COPD medications. The distribution of adherence to COPD bronchodilator medication revealed significant differences $(P<0.001)$ between the admission and the non-readmission group.

With respect to comorbid conditions of interest at baseline (depression, pulmonary vascular disease, CKD, heart failure/heart disease), the readmission group had a statistically significant higher proportion of patients with at least one comorbidity $(60.2 \%)$, compared to the non-readmission group (43.8\%, $P<0.001)$. Heart-related issues were common (40.6\%), followed by depression (21.4\%) and anemia $(17.8 \%)$ in the readmission group. Comparatively, the nonreadmission group revealed $26.9 \%, 15.9 \%$, and $9.0 \%$ in heart-related comorbidity, depression, and anemia, respectively. Readmitted patients also had a significantly larger COPD severity score, which encompasses COPD-related health care utilization and medications used by patients (25.5 vs $23.4 ; P<0.001)$.

Index hospitalization attributes also revealed significant differences between the two groups. Readmitted patients had a longer mean length of stay for index hospitalization (4.2 days) compared to 3.6 days for patients without readmissions. Dyspnea/shortness of breath was the most commonly found concurrent medical condition of interest (40.5\%) in the 


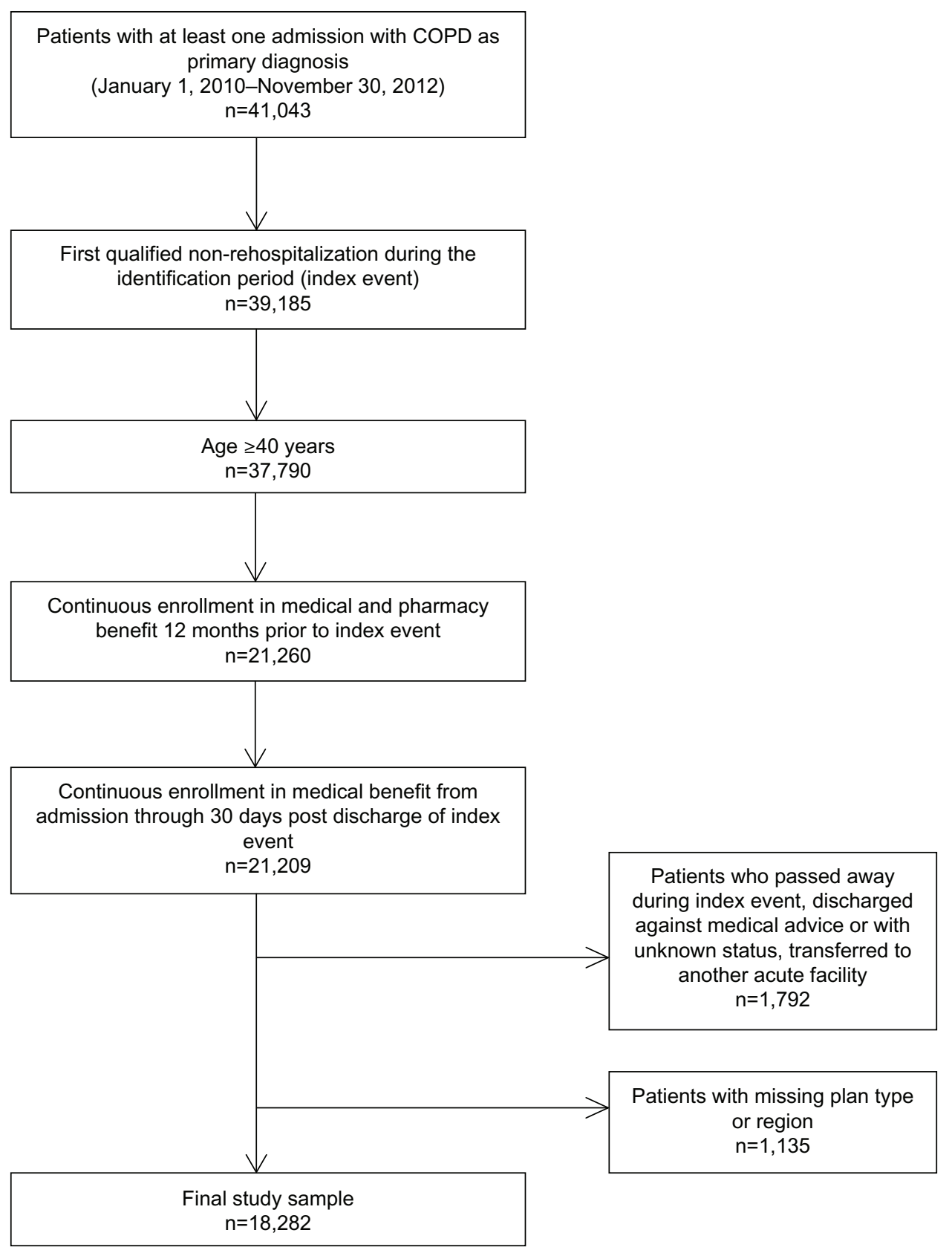

Figure I Patient flow diagram.

Abbreviation: COPD, chronic obstructive pulmonary disease.

readmitted group and was significantly higher compared to the non-readmitted group (36.4\%). Furthermore, a greater percentage of patients in the readmission group (24.1\%) had an initial ICU stay, compared to the non-readmitted patients (19.3\%).

Results of the logistic regression model for 30-day all-cause unplanned readmissions are shown in Figure 2. Demographic variables did not prove to be statistically significant, nor did adherence to COPD bronchodilator medication. However, baseline comorbid conditions were all significant, and each one had an odds ratio $(\mathrm{OR})$ of $>1$, with anemia having an OR of 1.6 (95\% CI 1.36-1.88) followed by heart failure/heart disease (OR 1.51, 95\% CI 1.33-1.71). The other significant findings from the logistic regression model were COPD severity score (OR 1.27, 95\% CI 1.17-1.37), length of stay for index hospitalization (OR 1.02, 95\% CI 1.00-1.03), and ICU stay (OR 1.19, 95\% CI 1.04-1.36). Results of the logistic regression model for the other two outcomes (ie, 30-day unplanned readmissions with COPD as primary or with COPD as any diagnosis) are given in Figures S1 and S2. To assess performance of the readmission models, $c$-statistics 
Table I Thirty-day all-cause unplanned readmission after an initial COPD-caused hospitalization: baseline and index hospitalization characteristics

\begin{tabular}{|c|c|c|c|c|}
\hline Variables & $\begin{array}{l}\text { All } \\
(n=18,282)\end{array}$ & $\begin{array}{l}\text { Readmission } \\
\text { group } \\
(n=I, 332)\end{array}$ & $\begin{array}{l}\text { Non-readmission } \\
\text { group } \\
(n=\mid 6,950)\end{array}$ & $P$-value ${ }^{a}$ \\
\hline \multicolumn{5}{|l|}{ Baseline characteristics } \\
\hline Age (years), mean (SD) & $56.6(5.8)$ & $57.0(5.7)$ & $56.5(5.8)$ & 0.006 \\
\hline Sex, n (\%) & & & & 0.020 \\
\hline Male & $6,869(37.6)$ & $540(40.5)$ & $6,329(37.3)$ & \\
\hline Female & $\mathrm{II}, 4 \mathrm{I} 3(62.4)$ & $792(59.5)$ & $10,62 \mid(62.7)$ & \\
\hline Plan type, n (\%) & & & & 0.032 \\
\hline Fee for service & I5,848 (86.7) & $\mathrm{I}, 129(84.8)$ & $14,7 \mid 9(86.8)$ & \\
\hline HMO and POS capitation & $2,434(13.3)$ & $203(15.2)$ & $2,23 \mid(\mid 3.2)$ & \\
\hline Region, $\mathrm{n}(\%)$ & & & & 0.703 \\
\hline Northeast & $2,293(12.5)$ & $165(12.4)$ & $2,128(12.6)$ & \\
\hline North central & $6,528(35.7)$ & $491(36.9)$ & $6,037(35.6)$ & \\
\hline South & $7,720(42.2)$ & $559(42.0)$ & $7,161(42.2)$ & \\
\hline West & I,74I (9.5) & II $7(8.8)$ & $1,624(9.6)$ & \\
\hline Influenza vaccine, $\mathrm{n}(\%)$ & $4,015(22.0)$ & $34 \mid(25.6)$ & $3,674(21.7)$ & $<0.001$ \\
\hline Adherence to COPD bronchodilator medication, $\mathrm{n}(\%)$ & & & & $<0.001$ \\
\hline $\mathrm{PDC}<0.8$ & $7,338(40.1)$ & $569(42.7)$ & $6,769(39.9)$ & \\
\hline $\mathrm{PDC} \geq 0.8$ & $5,648(30.9)$ & $452(33.9)$ & $5,196(30.7)$ & \\
\hline No medication & $5,296(29.0)$ & $3 I I(23.3)$ & $4,985(29.4)$ & \\
\hline \multicolumn{5}{|l|}{ Baseline comorbidities, n (\%) } \\
\hline Any (depression, pulmonary vascular disease, chronic & $8,234(45.0)$ & $802(60.2)$ & $7,432(43.8)$ & $<0.001$ \\
\hline \multicolumn{5}{|l|}{ kidney disease, anemia, or heart failure/heart disease) } \\
\hline Depression & $2,983(16.3)$ & $285(21.4)$ & $2,698(I 5.9)$ & $<0.001$ \\
\hline Pulmonary vascular disease & $\mathrm{I}, 0 \mathrm{II}(5.5)$ & $137(10.3)$ & $874(5.2)$ & $<0.001$ \\
\hline Chronic kidney disease & $\mathrm{I}, 280(7.0)$ & $169(12.7)$ & $\mathrm{I}, \mathrm{II} \mathrm{I}(6.6)$ & $<0.001$ \\
\hline Anemia & $\mathrm{I}, 766(9.7)$ & $237(17.8)$ & $\mathrm{I}, 529(9.0)$ & $<0.001$ \\
\hline Heart failure/heart disease & $5,102(27.9)$ & $54 \mid(40.6)$ & $4,56 \mid(26.9)$ & $<0.001$ \\
\hline Statin use, n (\%) & $4,912(26.9)$ & $385(28.9)$ & $4,527(26.7)$ & 0.082 \\
\hline COPD severity score, mean (SD) & $23.6(8.2)$ & $25.5(9.4)$ & $23.4(8.1)$ & $<0.001$ \\
\hline COPD severity score, median (IQR) & $20.9(9.0)$ & $22.8(11.3)$ & $20.8(8.8)$ & \\
\hline \multicolumn{5}{|l|}{ Index hospitalization characteristics } \\
\hline Index hospitalization year, n (\%) & & & & 0.033 \\
\hline 2010 & $7,389(40.4)$ & $583(43.8)$ & $6,806(40.2)$ & \\
\hline 2011 & $6,118(33.5)$ & $425(31.9)$ & $5,693(33.6)$ & \\
\hline 2012 & $4,775(26.1)$ & $324(24.3)$ & 4,45 I (26.3) & \\
\hline Length of stay (days), mean (SD) & $3.7(3.8)$ & $4.2(3.6)$ & $3.6(3.8)$ & $<0.001$ \\
\hline Winter season, n (\%) & $6,958(38.1)$ & $504(37.8)$ & $6,454(38.1)$ & 0.863 \\
\hline Dyspnea/shortness of breath, $n(\%)$ & $6,715(36.7)$ & $540(40.5)$ & $6,175(36.4)$ & 0.003 \\
\hline Pneumonia, n (\%) & $3,914(21.4)$ & $294(22.1)$ & $3,620(21.4)$ & 0.540 \\
\hline ICU stay, n (\%) & $3,598(19.7)$ & $321(24.1)$ & $3,277(19.3)$ & $<0.001$ \\
\hline Ventilator use, n (\%) & $17,253(94.4)$ & $\mathrm{I}, 272(95.5)$ & $|5,98|(94.3)$ & 0.065 \\
\hline Oxygen therapy, n (\%) & $408(2.2)$ & $26(2.0)$ & $382(2.3)$ & 0.473 \\
\hline
\end{tabular}

Note: ${ }^{a}$ Chi square tests used for categorical variables; $t$-tests or Mann-Whitney $U$ tests used for continuous variables.

Abbreviations: COPD, chronic obstructive pulmonary disease; HMO, health maintenance organizations; ICU, intensive care unit; IQR, interquartile range; PDC, proportion of days covered; POS, Point-of-Service Plan; SD, standard deviation.

assessing predictive accuracy and modified HosmerLemeshow goodness-of-fit tests ${ }^{40,41}$ were estimated, using the full dataset (Table 2).

In cross-validation analysis, the logistic regression model in the training set ( $75 \%$ of the total study sample) showed moderate ability to discriminate for 30-day unplanned readmissions for all-cause events, as measured by the $c$-statistic
(0.64, 95\% CI 0.63-0.65). The models for unplanned readmissions with COPD as primary or any diagnosis showed similar results with values of 0.65 (95\% CI $0.64-0.67)$ and 0.65 (95\% CI 0.63-0.66), respectively. In the validation sample, comparable results were found, and the model for unplanned readmissions for all-cause events resulted in a value of 0.62 (95\% CI 0.59-0.65). Similar model fit numbers were seen 


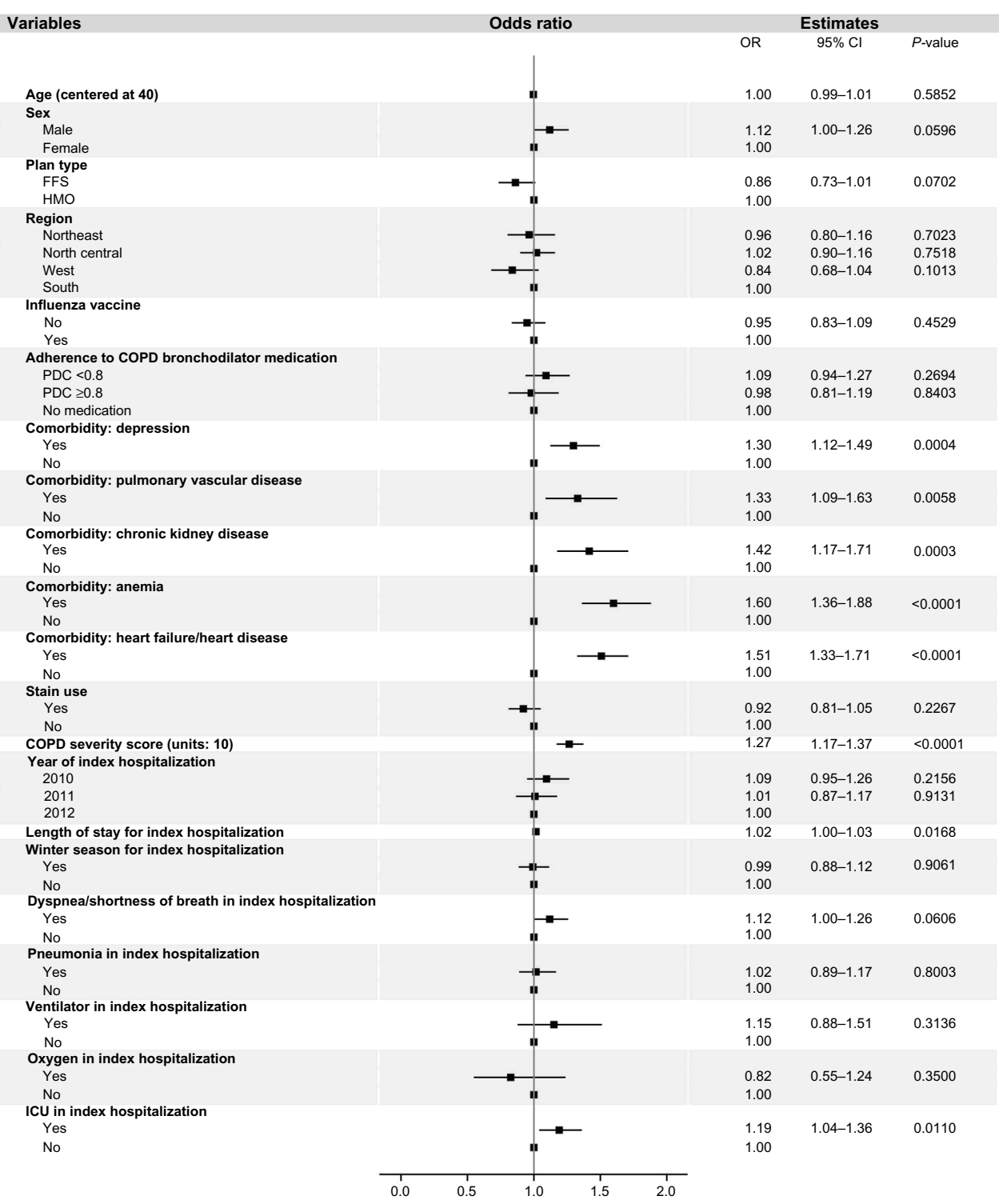

Figure 2 Association between predictors and 30-day all-cause unplanned readmission after an initial COPD-caused hospitalization.

Abbreviations: $\mathrm{Cl}$, confidence interval; COPD, chronic obstructive pulmonary disease; FFS, fee-for-service; HMO, health maintenance organizations; ICU, intensive care unit; OR, odds ratio; PDC, proportion of days covered.

for the validation samples of COPD readmission as primary diagnosis, with a $c$-statistic of $0.62(95 \%$ CI $0.58-0.66)$ and with any diagnosis with $c=0.63(95 \% \mathrm{CI} 0.60-0.66)$.

Table 3 shows the results of the dominance analysis. Dominance analysis in the three unplanned readmission

Table 2 Full model goodness of fit

\begin{tabular}{|c|c|c|}
\hline $\begin{array}{l}\text { Outcomes: unplanned } \\
\text { readmissions within } \\
30 \text { days of index } \\
\text { discharge date }\end{array}$ & c-statistic & $\begin{array}{l}\text { Modified } \\
\text { Hosmer-Lemeshow } \\
\text { goodness-of-fit test } \\
(P \text {-value) }\end{array}$ \\
\hline All-cause & 0.6355 & 0.7829 \\
\hline COPD as primary diagnosis & 0.6477 & 0.8076 \\
\hline COPD as any diagnosis & 0.6431 & 0.9772 \\
\hline
\end{tabular}

Abbreviation: COPD, chronic obstructive pulmonary disease. models revealed similar patterns in terms of importance of the variables in predicting unplanned readmissions. In the primary model of interest, namely all-cause readmissions, heart failure/heart disease, anemia, and COPD severity score were the three highest ranked variables among the 21 predictors evaluated and accounted for $56 \%$ of the predicted variance $(21.67 \%, 17.93 \%$, and $16.74 \%$, respectively). Those were followed by other baseline medical conditions. Many of the demographic and index hospitalization attributes were among the lowest-ranked items.

In the model predicting unplanned readmissions with COPD as the primary diagnosis, COPD severity score, adherence to COPD bronchodilator medication, and heart failure/ heart disease were identified as most important in predicting 
Table 3 Importance of predictors for 30-day unplanned readmission after an initial COPD-caused hospitalization

\begin{tabular}{|c|c|c|c|c|c|c|}
\hline \multirow[t]{2}{*}{ Variables } & \multicolumn{2}{|l|}{ All-cause } & \multicolumn{2}{|c|}{ COPD as primary diagnosis } & \multicolumn{2}{|c|}{ COPD as any diagnosis } \\
\hline & $\begin{array}{l}\text { Standardized } \\
\text { weight }^{\mathrm{a}}\end{array}$ & Rank & $\begin{array}{l}\text { Standardized } \\
\text { weight }^{\mathrm{a}}\end{array}$ & Rank & $\begin{array}{l}\text { Standardized } \\
\text { weight }^{\mathrm{a}}\end{array}$ & Rank \\
\hline Heart failure/heart disease & 0.2167 & 1 & 0.1496 & 3 & 0.2030 & 2 \\
\hline Anemia & 0.1793 & 2 & 0.0667 & 5 & 0.0912 & 4 \\
\hline COPD severity score (per 10 unit increase) & 0.1674 & 3 & 0.3031 & 1 & 0.3076 & 1 \\
\hline Chronic kidney disease & 0.0974 & 4 & 0.0021 & 19 & 0.0169 & 9 \\
\hline Pulmonary vascular disease & 0.0725 & 5 & 0.0054 & 16 & 0.0476 & 6 \\
\hline Depression & 0.0598 & 6 & 0.0406 & 6 & 0.0670 & 5 \\
\hline Adherent to COPD bronchodilator medication & 0.0388 & 7 & 0.1899 & 2 & 0.1318 & 3 \\
\hline Length of stay for index hospitalization & 0.0362 & 8 & 0.0031 & 17 & 0.0126 & 11 \\
\hline ICU stay & 0.0340 & 9 & 0.0165 & 9 & 0.0280 & 7 \\
\hline Dyspnea/shortness of breath & 0.0192 & 10 & 0.0023 & 18 & 0.0101 & 15 \\
\hline Sex & 0.0149 & II & 0.0154 & 11 & 0.0103 & 14 \\
\hline Index hospitalization year & 0.0134 & 12 & 0.0297 & 7 & 0.0109 & 13 \\
\hline Plan type & 0.0127 & 13 & 0.0935 & 4 & 0.0161 & 10 \\
\hline Region & 0.0096 & 14 & 0.0202 & 8 & 0.0169 & 8 \\
\hline Not received influenza vaccine & 0.0091 & 15 & 0.0020 & 20 & 0.0036 & 18 \\
\hline Ventilator use & 0.0064 & 16 & 0.0105 & 14 & 0.0058 & 16 \\
\hline Age (centered at 40) & 0.0050 & 17 & 0.0120 & 13 & 0.0122 & 12 \\
\hline Statin use & 0.0034 & 18 & 0.0057 & 15 & 0.0053 & 17 \\
\hline Oxygen therapy & 0.0032 & 19 & 0.0144 & 12 & 0.0017 & 19 \\
\hline Pneumonia & 0.0007 & 20 & 0.0157 & 10 & 0.0009 & 20 \\
\hline Winter season & 0.0001 & 21 & 0.0016 & 21 & 0.0005 & 21 \\
\hline
\end{tabular}

Notes: aStandardized weight is the general dominance weight from McFadden $R^{233}$ normed or standardized to be out of $100 \%{ }^{44}$ The standard weights might not add up to I due to rounding errors. The shaded area highlights the top 3 predictors ranked.

Abbreviations: COPD, chronic obstructive pulmonary disease; ICU, intensive care unit.

readmissions and accounted for $64 \%$ of the predicted variance $(30.31 \%, 18.99 \%$, and $14.96 \%$, respectively). Some baseline comorbidities (eg, pulmonary vascular disease, $\mathrm{CKD}$ ) were not as important as in the all-cause readmission model, which made intuitive sense. The model of unplanned readmissions with COPD as any diagnosis showed similar results, with COPD severity score, heart failure/heart disease, and adherence to COPD bronchodilator medication as the top three ranked items and accounted for $64 \%$ of the predicted variance $(30.76 \%, 20.3 \%$, and $13.18 \%$, respectively).

\section{Discussion}

Although studies of hospital readmission events in COPD have been published previously, the present study evaluated variables not previously examined and used a novel approach to evaluate predictors' relative importance. We examined three outcomes of interest, depending on unplanned readmission diagnosis, which helped elucidate background factors that predict readmission events in COPD patients. In those who had an unplanned all-cause readmission, which is most relevant to CMS reimbursement policies, a readmission rate of $7.3 \%$ was observed, compared to $2.6 \%$ readmission rate with COPD as primary diagnosis. Similar all-cause readmission rates within 30 days have been previously reported $-8.25 \%$ was found in one study using health care administrative claims database, while a higher national estimate of $22 \%$ was found in the Medicare population using the State Inpatient Databases, Healthcare Cost and Utilization Project, Agency for Healthcare Research and Quality. ${ }^{719}$ These differences may be attributable to different study populations, as patients in Medicare generally tend to be older and of poorer health. Furthermore, nuances in study design, such as methods used to identify COPD cohorts, differences in outcome variable definitions (readmission vs unplanned readmission), or different data sources, may have led to these discrepancies.

In this study, comorbidities at baseline seemed to play an important role, as the unplanned readmission group in each study outcome had significantly higher proportions of comorbidities compared to those who did not have a readmission event (except for CKD in those with COPD as a primary readmission diagnosis). The relative importance of heart failure/heart disease, depression, and anemia has been established in previous studies. ${ }^{22-26,28}$ This effect of baseline medical conditions prior to an index hospitalization influencing COPD readmissions has been previously documented, ${ }^{19,28}$ and strongly suggests the importance of care coordination across the inpatient-outpatient continuum as a 
means to prevent unplanned hospital readmissions among patients with COPD.

Overall, 29.0\% of COPD patients had a value of " 0 " for PDC at baseline labeled as "no medication" (23.3\% for the admission group vs $29.4 \%$ for the non-readmission group). No medication at baseline indicated that their providers did not prescribe COPD medication, they did not take COPD medication (completely non-adherent), or they were first diagnosed with COPD during their index hospitalization, an acute, severe, and expensive exacerbation event. By comparison, Mapel et $\mathrm{al}^{42}$ reported that $18 \%$ of COPD patients enrolled in a managed care system in southwestern USA were first diagnosed in hospital.

To the authors' knowledge, this study is the first to apply dominance analysis to regression modeling of health care resource use. Dominance-analysis-derived standardized weight estimates showed that $56 \%$ of the predicted variance in unplanned all-cause readmissions could be attributable to the three top-ranked predictors - heart failure/heart disease, anemia, and COPD severity score.

With COPD as a primary diagnosis or with COPD as any diagnosis, more COPD-specific variables were ranked higher by dominance analysis, with COPD medication adherence becoming increasingly important. The three most important predictors - COPD severity score, adherence to COPD bronchodilator medication, and heart failure/heart disease accounted for $64 \%$ of the predicted variance in unplanned COPD-related readmissions.

Health care decision making typically involves problems marked by high levels of uncertainty around the relative importance of predictors of desired clinical outcomes. Dominance analysis provides a means to evaluate and rank the importance of predictors. As such, it may be a useful decision-making tool, supplementing knowledge following from regression models and risk scores generated by these models. Focusing on specific, modifiable variables found to be important through dominance analysis may be of help in planning readmission reduction interventions by both CMS and commercial payers.

This study has several limitations. First, conclusions are limited to the commercially insured population in the US. The readers should be cautious in generalizing the study results to the US Medicare population or countries with singlepayer systems. Second, socioeconomic variables or clinical variables such as smoking status or body mass index (BMI) were not available in administrative claims for inclusion in the models. Third, a value of " 0 " for PDC could indicate that providers did not prescribe COPD medication, that patients did not fill their prescriptions (complete non-adherence), or that patients were first diagnosed with COPD during their index hospitalization. Those three scenarios cannot be differentiated using administrative claims data. Fourth, typical claims data limitations may exist such as potentially inaccurate coding of diagnoses or procedures. Fifth, influenza vaccination or oxygen therapy is often underestimated using claims. Sixth, by design, only the first COPD-related hospitalization and the subsequent 30 days after index discharge for a particular patient were used, even if a patient had several such "index" hospitalizations in the 3-year study range. Finally, bootstrapping to obtain the confidence intervals summarizing variability in assigned relative importance estimates ${ }^{33,36,43}$ was not performed, due to computational intensity. With 21 predictors in the logistic model, dominance analysis requires assessment of 2.1 million submodels to account for all possible predictor combinations. This precluded the additional step of bootstrapping.

\section{Conclusion}

This study found a 7.3\% unplanned readmission rate within 30 days for all-cause events following an initial COPD hospitalization among commercial beneficiaries. Significant predictors for unplanned readmissions included serious comorbidities like heart failure, severity of COPD, and index hospitalization characteristics. Results from dominance analysis suggest looking beyond COPD-specific complications and focusing on comorbid conditions highly associated with COPD in order to lower all-cause unplanned readmissions. For payers targeting cause-specific COPD readmissions, the aforementioned variables remain important, but increasing emphasis should be paid to COPD-specific medication adherence.

\section{Acknowledgments}

The authors thank Keiko Higuchi for her support of this project, and a couple of anonymous reviewers for their comments. All errors remain the authors'.

\section{Author contributions}

All of the authors had complete control and authority over the study design, data analysis, data interpretation, and manuscript preparation. All of authors have read and approved the entire manuscript, and take full responsibility for the accuracy of the analyses.

\section{Disclosure}

This study was financially supported by Novartis Pharmaceuticals Corporation (East Hanover, NJ, USA). Tzy-Chyi 
Yu and Stephen Arcona are employees and stockholders of Novartis Pharmaceuticals Corporation. Huanxue Zhou is an employee of KMK Consulting Inc and provides services to Novartis Pharmaceuticals Corporation. Kangho Suh was an Outcomes Research Fellow of Novartis Pharmaceuticals Corporation at the time this study was conducted. The authors report no other conflicts of interest in this work.

\section{References}

1. Minott J. Reducing hospital readmissions. AcademyHealth website; 2008. Available from: http://www.academyhealth.org/files/publications/ Reducing_Hospital_Readmissions.pdf. Accessed July 29, 2014.

2. Rau J. Medicare to penalize 2,217 hospitals for excess readmissions. Kaiser health news website; 2012. Available from: http://www. kaiserhealthnews.org/stories/2012/august/13/medicare-hospitalsreadmissions-penalties.aspx. Accessed July 29, 2014.

3. Aetna, Genesis HealthCare Take Aim At Preventing Hospital Readmissions. Aetna Website; 2011. Available from: https://www1. aetna.com/news/newsReleases/2011/0810_Aetna-Genesis_HospitalReadmissions.html. Accessed August 15, 2014.

4. Carroll J. It's in insurers' interest to help cut readmissions. Manag Care. 2012;21(10):5-6.

5. Adamy J. WellPoint shakes up hospital payments. Wall Street Journal website; 2011. Available from: http://online.wsj.com/news/articles/SB 10001424052748704281504576325163218629124. Accessed July 29, 2014.

6. Cigna Teams With CareCentrix to Reduce Hospital Readmissions. Cigna Website; 2010. Available from: http://newsroom.cigna.com/ article_display.cfm?article_id=1222. Accessed August 15, 2014.

7. Hines AL, Barrett ML, Jiang HJ, Steiner CA. Conditions with the largest number of adult hospital readmissions by payer, 2011. HCUP Statistical Brief \#172. Rockville, MD: Agency for Healthcare Research and Quality; 2014. Available from: http://www.hcup-us.ahrq.gov/ reports/statbriefs/sb172-Conditions-Readmissions-Payer.pdf. Accessed August 15, 2014.

8. Readmission reduction program. Centers for Medicare and Medicaid Services website; 2014. Available from: http://www.cms.gov/Medicare/ Medicare-Fee-for-Service-Payment/AcuteInpatientPPS/ReadmissionsReduction-Program.html. Accessed July 29, 2014.

9. Medicare Payment Advisory Commission. Report to Congress: reforming the delivery system. Washington, DC; 2008. Available from: http://www.medpac.gov/documents/reports/Jun08_EntireReport. pdf?sfvrsn=0. Accessed July 29, 2014.

10. US National Institutes of Health, National Heart Lung and Blood Institute. Morbidity and mortality: 2012 chart book on cardiovascular, lung, and blood diseases. Bethesda, MD; 2012. Available from: http:// www.nhlbi.nih.gov/files/docs/research/2012_ChartBook.pdf. Accessed August 15, 2014.

11. Elixhauser A, Au DH, Podulka J. Readmissions for chronic obstructive pulmonary disease, 2008. HCUP Statistical Brief\#121. Rockville, MD: Agency for Healthcare Research and Quality; 2011. Available from: http://www.hcup-us.ahrq.gov/reports/statbriefs/sb121.pdf. Accessed July 29, 2014.

12. Torio CM, Andrews RM. National inpatient hospital costs: the most expensive conditions by payer, 2011. Statistical Brief \#160. Rockville, MD: Agency for Healthcare Research and Quality; 2013. Available from: http://www.hcup-us.ahrq.gov/reports/statbriefs/sb160.jsp. Accessed July 29, 2014.

13. Amarasingham R, Moore BJ, Tabak YP, et al. An automated model to identify heart failure patients at risk for 30-day readmission or death using electronic medical record data. Med Care. 2010;48(11):981-988.
14. Keenan PS, Normand SL, Lin Z, et al. An administrative claims measure suitable for profiling hospital performance on the basis of 30-day all-cause readmission rates among patients with heart failure. Circ Cardiovasc Qual Outcomes. 2008;1(1):29-37.

15. Krumholz HM, Merrill AR, Schone EM, et al. Patterns of hospital performance in acute myocardial infarction and heart failure 30-day mortality and readmission. Circ Cardiovasc Qual Outcomes. 2009;2(5): 407-413.

16. Garcia-Aymerich J, Farrero E, Félez MA, et al; Estudi del Factors de Risc d'Agudització de la MPOC investigators. Risk factors of readmission to hospital for a COPD exacerbation: a prospective study. Thorax. 2003;58(2):100-105.

17. Garcia-Aymerich J, Hernandez C, Alonso A, et al. Effects of an integrated care intervention on risk factors of COPD readmission. Respir Med. 2007;101(7):1462-1469.

18. Puhan MA, Scharplatz M, Troosters T, Steurer J. Respiratory rehabilitation after acute exacerbation of COPD may reduce risk for readmission and mortality - a systematic review. Respir Res. 2005;6:54.

19. Baker CL, Zou KH, Su J. Risk assessment of readmissions following an initial COPD-related hospitalization. Int J Chron Obstruct Pulmon Dis. 2013;8:551-559.

20. Truven Health Analytics. 2012. Available from: http://truvenhealth. com/your-healthcare-focus/analytic-research/marketscan-researchdatabases. Accessed July 23, 2014.

21. Grosso LM, Lindenauer P, Wang C, et al. Hospital-level 30-day readmission following admission for an acute exacerbation of chronic obstructive pulmonary disease. Centers for Medicare and Medicaid Services website. 2011. Available from: http://www.cms.gov/Medicare/QualityInitiatives-Patient-Assessment-Instruments/HospitalQualityInits/ Measure-Methodology.html. Accessed July 29, 2014.

22. Barba R, de Casasola GG, Marco J, et al. Anemia in chronic obstructive pulmonary disease: a readmission prognosis factor. Curr Med Res Opin. 2012;28(4):617-622.

23. Holguin F, Folch E, Redd SC, Mannino DM. Comorbidity and mortality in COPD-related hospitalizations in the United States, 1979 to 2001. Chest. 2005;128(4):2005-2011.

24. Nantsupawat T, Limsuwat C, Nugent K. Factors affecting chronic obstructive pulmonary disease early rehospitalization. Chron Respir Dis. 2012;9(2):93-98.

25. Ng TP, Niti M, Tan WC, Cao Z, Ong KC, Eng P. Depressive symptoms and chronic obstructive pulmonary disease: effect on mortality, hospital readmission, symptom burden, functional status, and quality of life. Arch Intern Med. 2007;167(1):60-67.

26. Xu W, Collet JP, Shapiro S, et al. Independent effect of depression and anxiety on chronic obstructive pulmonary disease exacerbations and hospitalizations. Am J Respir Crit Care Med. 2008;178(9):913-920.

27. Shams I, Ajorlou S, Yang K. A predictive analytics approach to reducing 30-day avoidable readmissions among patients with heart failure, acute myocardial infarction, pneumonia, or COPD. Health Care Manag Sci. Epub 2014 May 3.

28. Sharif R, Parekh TM, Pierson KS, Kuo Y-F, Sharma G. Predictors of early readmission among patients aged 40 to 64 years hospitalized for chronic obstructive pulmonary disease. Ann Am Thorac Soc. 2014;11(5): 685-694.

29. Wu EQ, Birnbaum HG, Cifaldi M, Kang Y, Mallet D, Colice G. Development of a COPD severity score. Curr Med Res Opin. 2006; 22(9):1679-1687.

30. Laratta CR, van Eeden S. Acute exacerbation of chronic obstructive pulmonary disease: cardiovascular links. Biomed Res Int. 2014;2014:18.

31. Nau DP. Proportion of days covered (PDC) as a preferred method of measuring medication adherence. 2012. Available from: http://ep.yimg. com/ty/cdn/epill/pdcmpr.pdf. Accessed August 15, 2014.

32. Harrell FE Jr, Lee KL, Mark DB. Multivariable prognostic models: issues in developing models, evaluating assumptions and adequacy, and measuring and reducing errors. Stat Med. 1996;15(4): 361-387. 
33. Azen R, Traxel N. Using dominance analysis to determine predictor importance in logistic regression. J Educ Behav Stat. 2009;34: 319-347.

34. Johnson JW, Lebreton JM. History and use of relative importance indices in organizational research. Organ Res Meth. 2004;7:238-257.

35. Johnson JW. A heuristic method for estimating the relative weight of predictor variables in multiple regression. Multivariate Behav Res. 2000;35(1):1-19.

36. Grömping U. Estimators of relative importance in linear regression based on variance decomposition. Am Stat. 2007;61(2):139-147.

37. Budescu DV. Dominance analysis: a new approach to the problem of relative importance of predictors in multiple regression. Pyschol Bull. 1993;114:542-551.

38. Budescu DV, Azen R. Beyond global measures of relative importance: some insights from dominance analysis. Organ Res Meth. 2004;7: 341-350.

39. Lebreton JM, Binning JF, Adorno AJ, Melcher KM. Importance of personality and job-specific affect for predicting job attitudes and withdrawal behavior. Organ Res Meth. 2004;7(3):300-325.
40. Paul P, Pennell ML, Lemeshow S. Standardizing the power of the Hosmer-Lemeshow goodness of fit test in large data sets. Stat Med. 2013;32(1):67-80.

41. Steyerberg EW, Vickers AJ, Cook NR, et al. Assessing the performance of prediction models: a framework for traditional and novel measures. Epidemiology. 2010;21(1):128-138.

42. Mapel DW, Robinson SB, Dastani HB, Shah H, Phillips AL, Lydick E. The direct medical costs of undiagnosed chronic obstructive pulmonary disease. Value Health. 2008;11(4):628-636

43. Tonidandel S, Lebreton JM. Relative importance analysis: a useful supplement to regression analysis. J Bus Psychol. 2011;26:1-9.

44. Luchman JN. DOMIN: Stata module to conduct dominance analysis. 2013. Available from: http://fmwww.bc.edu/repec/bocode/d/domin sthlp. Accessed August 29, 2014. 


\section{Supplementary materials}

Table SI COPD as primary diagnosis 30-day unplanned readmission after an initial COPD-caused hospitalization: baseline and index hospitalization characteristics

\begin{tabular}{|c|c|c|c|c|}
\hline Variables & $\begin{array}{l}\text { All } \\
(n=18,282)\end{array}$ & $\begin{array}{l}\text { Readmission } \\
\text { group } \\
(n=480)\end{array}$ & $\begin{array}{l}\text { Non-readmission } \\
\text { group } \\
(n=\mid 7,802)\end{array}$ & $P$-value ${ }^{a}$ \\
\hline \multicolumn{5}{|l|}{ Baseline characteristics } \\
\hline Age (years), mean (SD) & $56.6(5.8)$ & $57.2(5.4)$ & $56.6(5.8)$ & 0.013 \\
\hline Sex, n (\%) & & & & 0.112 \\
\hline Male & $6,869(37.6)$ & $197(4 \mid .0)$ & $6,627(37.6)$ & \\
\hline Female & $1 \mathrm{I}, 4 \mathrm{I} 3(62.4)$ & $283(59.0)$ & II, I30 (62.4) & \\
\hline Plan type, n (\%) & & & & $<0.00$ I \\
\hline Fee for service & I5,848 (86.7) & $388(80.8)$ & I5,460 (86.8) & \\
\hline HMO and POS capitation & $2,434(13.3)$ & $92(19.2)$ & $2,342(13.2)$ & \\
\hline Region, $\mathrm{n}(\%)$ & & & & 0.569 \\
\hline Northeast & $2,293(12.5)$ & $67(14.0)$ & $2,226(I 2.5)$ & \\
\hline North central & $6,528(35.7)$ & $179(37.3)$ & $6,349(35.7)$ & \\
\hline South & $7,720(42.2)$ & $190(39.6)$ & $7,530(42.3)$ & \\
\hline West & $\mathrm{I}, 74 \mathrm{I}(9.5)$ & $44(9.2)$ & $1,697(9.5)$ & \\
\hline Influenza vaccine, $\mathrm{n}(\%)$ & $4,015(22.0)$ & $116(24.2)$ & $3,899(21.9)$ & 0.237 \\
\hline Adherence to COPD bronchodilator medication, $\mathrm{n}(\%)$ & & & & $<0.001$ \\
\hline $\mathrm{PDC}<0.8$ & $7,338(40.1)$ & $192(40.0)$ & $7,146(40.1)$ & \\
\hline $\mathrm{PDC} \geq 0.8$ & $5,648(30.9)$ & $204(42.5)$ & $5,444(30.6)$ & \\
\hline No medication & $5,296(29.0)$ & $84(17.5)$ & $5,212(29.3)$ & \\
\hline \multicolumn{5}{|l|}{ Baseline comorbidities, n (\%) } \\
\hline Any (depression, pulmonary vascular disease, chronic & $8,234(45.0)$ & $272(56.7)$ & $7,962(44.7)$ & $<0.001$ \\
\hline \multicolumn{5}{|l|}{ kidney disease, anemia, or heart failure/heart disease) } \\
\hline Depression & $2,983(16.3)$ & $100(20.8)$ & $2,883(16.2)$ & 0.007 \\
\hline Pulmonary vascular disease & $\mathrm{I}, 0 \mathrm{II}(5.5)$ & $37(7.7)$ & $974(5.5)$ & 0.034 \\
\hline Chronic kidney disease & $1,280(7.0)$ & $40(8.3)$ & $\mathrm{I}, 240(7.0)$ & 0.247 \\
\hline Anemia & $1,766(9.7)$ & $72(15.0)$ & $\mathrm{I}, 694(9.5)$ & $<0.001$ \\
\hline Heart failure/heart disease & $5,102(27.9)$ & $187(39.0)$ & $4,915(27.6)$ & $<0.001$ \\
\hline Statin use, $\mathrm{n}(\%)$ & $4,912(26.9)$ & $134(27.9)$ & $4,778(26.8)$ & 0.599 \\
\hline COPD severity score, mean (SD) & $23.6(8.2)$ & $26.9(9.5)$ & $23.5(8.2)$ & $<0.001$ \\
\hline COPD severity score, median (IQR) & $20.9(9.0)$ & $25.1(12.7)$ & $20.8(8.9)$ & \\
\hline \multicolumn{5}{|l|}{ Index hospitalization characteristics } \\
\hline Index hospitalization year, n (\%) & & & & 0.050 \\
\hline 2010 & $7,389(40.4)$ & $219(45.6)$ & $7,170(40.3)$ & \\
\hline 2011 & $6,118(33.5)$ & |4| (29.4) & $5,977(33.6)$ & \\
\hline 2012 & $4,775(26.1)$ & $120(25.0)$ & $4,655(26.1)$ & \\
\hline Length of stay (days), mean (SD) & $3.7(3.8)$ & $3.9(2.9)$ & $3.7(3.8)$ & 0.108 \\
\hline Winter season, $\mathrm{n}(\%)$ & $6,958(38.1)$ & $187(39.0)$ & $6,771(38.0)$ & 0.681 \\
\hline Dyspnea/shortness of breath, $n(\%)$ & $6,715(36.7)$ & $185(38.5)$ & $6,530(36.7)$ & 0.404 \\
\hline Pneumonia, n (\%) & $3,914(21.4)$ & $90(18.8)$ & $3,824(21.5)$ & 0.150 \\
\hline ICU stay, n (\%) & $3,598(19.7)$ & $111(23.1)$ & $3,487(19.6)$ & 0.054 \\
\hline Ventilator use, n (\%) & I7,253 (94.4) & $459(95.6)$ & I6,794 (94.3) & 0.227 \\
\hline Oxygen therapy, n (\%) & $408(2.2)$ & $7(1.5)$ & $40 I(2.3)$ & 0.245 \\
\hline
\end{tabular}

Note: ${ }^{2}$ Chi-square tests used for categorical variables; $t$-tests or Mann-Whitney $U$ tests used for continuous variables.

Abbreviations: COPD, chronic obstructive pulmonary disease; HMO, health maintenance organizations; POS, Point-of-Service Plan; PDC, proportion of days covered; $\mathrm{SD}$, standard deviation; IQR, interquartile range; ICU, intensive care unit. 
Table S2 COPD as any diagnosis 30-day unplanned readmission after an initial COPD-caused hospitalization: baseline and index hospitalization characteristics

\begin{tabular}{|c|c|c|c|c|}
\hline Variables & $\begin{array}{l}\text { All } \\
(n=\mid 8,282)\end{array}$ & $\begin{array}{l}\text { Readmission } \\
\text { group } \\
(n=I, 022)\end{array}$ & $\begin{array}{l}\text { Non-readmission } \\
\text { group } \\
(n=\mid 7,260)\end{array}$ & $P$-value ${ }^{a}$ \\
\hline \multicolumn{5}{|l|}{ Baseline characteristics } \\
\hline Age (years), mean (SD) & $56.6(5.8)$ & $57.2(5.5)$ & $56.5(5.8)$ & $<0.001$ \\
\hline Sex, n (\%) & & & & 0.063 \\
\hline Male & $6,869(37.6)$ & $4 \mid 2(40.3)$ & $6,457(37.4)$ & \\
\hline Female & II,4I3 (62.4) & $610(59.7)$ & $10,803(62.6)$ & \\
\hline Plan type, n (\%) & & & & 0.023 \\
\hline Fee for service & I5,848 (86.7) & $862(84.3)$ & |4,986 (86.8) & \\
\hline $\mathrm{HMO}$ and POS capitation & $2,434(13.3)$ & $160(15.7)$ & $2,274(13.2)$ & \\
\hline Region, $n(\%)$ & & & & 0.369 \\
\hline Northeast & $2,293(12.5)$ & $124(12.1)$ & $2,169(12.6)$ & \\
\hline North central & $6,528(35.7)$ & $391(38.3)$ & $6,137(35.6)$ & \\
\hline South & $7,720(42.2)$ & $416(40.7)$ & $7,304(42.3)$ & \\
\hline West & $\mathrm{I}, 74 \mathrm{I}(9.5)$ & 91 (8.9) & $\mathrm{I}, 650(9.6)$ & \\
\hline Influenza vaccine, n (\%) & $4,015(22.0)$ & $258(25.2)$ & $3,757(21.8)$ & 0.009 \\
\hline Adherence to COPD bronchodilator medication, $\mathrm{n}(\%)$ & & & & $<0.001$ \\
\hline $\mathrm{PDC}<0.8$ & $7,338(40.1)$ & $432(42.3)$ & $6,906(40.0)$ & \\
\hline $\mathrm{PDC} \geq 0.8$ & $5,648(30.9)$ & $397(38.8)$ & $5,25 I(30.4)$ & \\
\hline No medication & $5,296(29.0)$ & $193(18.9)$ & $5,103(29.6)$ & \\
\hline \multicolumn{5}{|l|}{ Baseline comorbidities, n (\%) } \\
\hline Any (depression, pulmonary vascular disease, chronic & $8,234(45.0)$ & $607(59.4)$ & $7,627(44.2)$ & $<0.001$ \\
\hline \multicolumn{5}{|l|}{ kidney disease, anemia, or heart failure/heart disease) } \\
\hline Depression & $2,983(16.3)$ & $224(21.9)$ & $2,759(16.0)$ & $<0.001$ \\
\hline Pulmonary vascular disease & $\mathrm{I}, 0 \mathrm{II}(5.5)$ & $101(9.9)$ & $910(5.3)$ & $<0.001$ \\
\hline Chronic kidney disease & $\mathrm{I}, 280(7.0)$ & $104(10.2)$ & $\mathrm{I}, \mathrm{I} 76(6.8)$ & $<0.001$ \\
\hline Anemia & $1,766(9.7)$ & $164(16.0)$ & $1,602(9.3)$ & $<0.001$ \\
\hline Heart failure/heart disease & $5,102(27.9)$ & $415(40.6)$ & $4,687(27.2)$ & $<0.001$ \\
\hline Statin use, n (\%) & $4,912(26.9)$ & $290(28.4)$ & $4,622(26.8)$ & 0.263 \\
\hline COPD severity score, mean (SD) & $23.6(8.2)$ & $26.6(9.7)$ & $23.4(8.1)$ & $<0.001$ \\
\hline COPD severity score, median (IQR) & $20.9(9.0)$ & $24.1(12.2)$ & $20.8(8.7)$ & \\
\hline \multicolumn{5}{|l|}{ Index hospitalization characteristics } \\
\hline Index hospitalization year, n (\%) & & & & 0.053 \\
\hline 2010 & $7,389(40.4)$ & $450(44.0)$ & $6,939(40.2)$ & \\
\hline 2011 & $6,118(33.5)$ & $323(31.6)$ & $5,795(33.6)$ & \\
\hline 2012 & $4,775(26.1)$ & $249(24.4)$ & $4,526(26.2)$ & \\
\hline Length of stay (days), mean (SD) & $3.7(3.8)$ & $4.0(3.2)$ & $3.6(3.8)$ & $<0.001$ \\
\hline Winter season, $\mathrm{n}(\%)$ & $6,958(38.1)$ & $393(38.5)$ & $6,565(38.0)$ & 0.789 \\
\hline Dyspnea/shortness of breath, $n$ (\%) & $6,715(36.7)$ & $406(39.7)$ & $6,309(36.6)$ & $0.04 I$ \\
\hline Pneumonia, n (\%) & $3,914(21.4)$ & $225(22.0)$ & $3,689(21.4)$ & 0.627 \\
\hline ICU stay, n (\%) & $3,598(19.7)$ & $245(24.0)$ & $3,353(19.4)$ & $<0.001$ \\
\hline Ventilator use, n (\%) & $17,253(94.4)$ & $976(95.5)$ & I6,277 (94.3) & 0.108 \\
\hline Oxygen therapy, n (\%) & $408(2.2)$ & $21(2.1)$ & $387(2.2)$ & 0.694 \\
\hline
\end{tabular}

Note: ${ }^{a}$ Chi-square tests used for categorical variables; $t$-tests or Mann-Whitney $U$ tests used for continuous variables.

Abbreviations: COPD, chronic obstructive pulmonary disease; HMO, health maintenance organizations; ICU, intensive care unit; IQR, interquartile range; PDC, proportion of days covered; POS, Point-of-Service Plan; SD, standard deviation. 


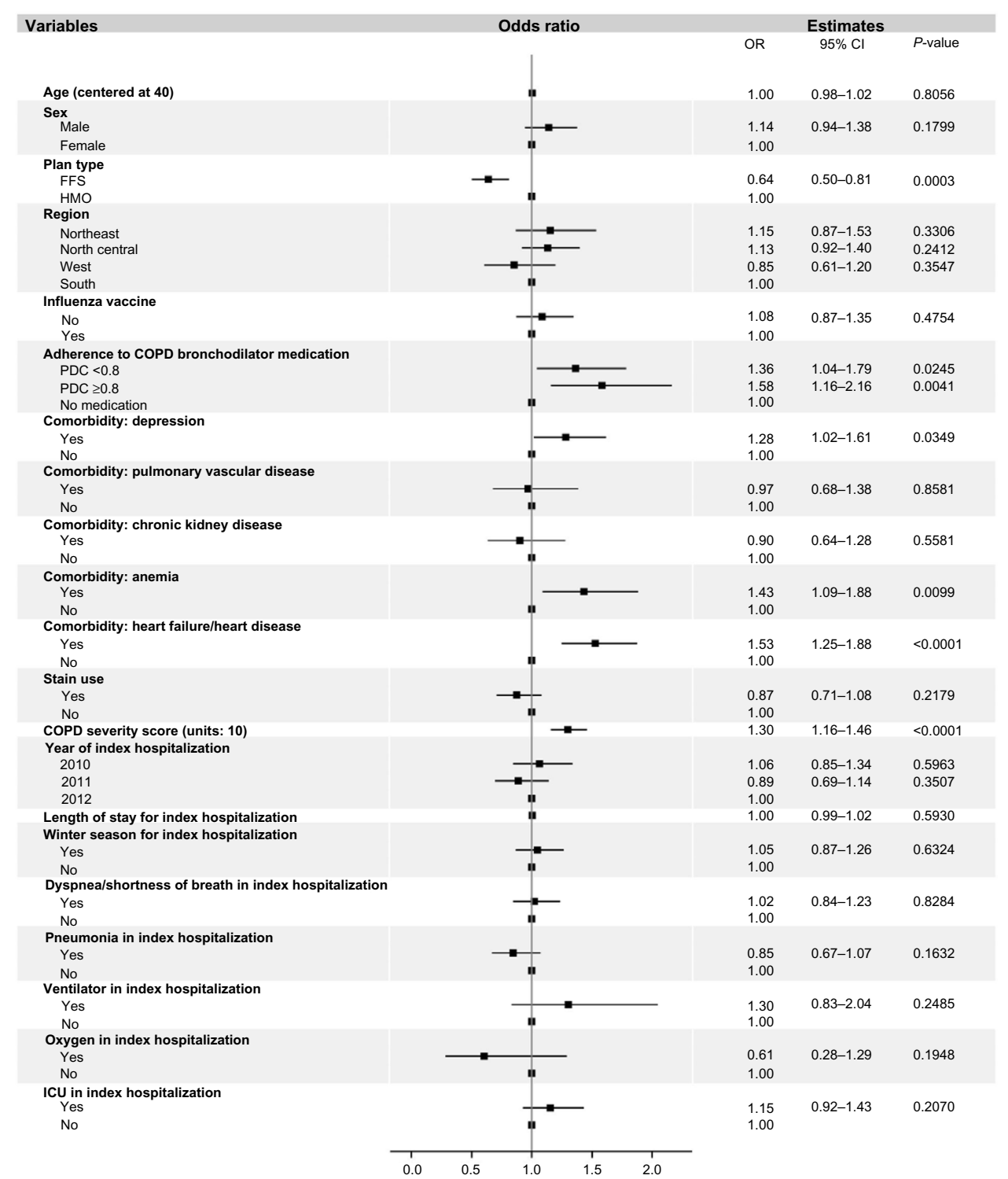

Figure SI Association between predictors and COPD as primary diagnosis 30-day unplanned readmission after an initial COPD-caused hospitalization. Abbreviations: $\mathrm{Cl}$, confidence interval; COPD, chronic obstructive pulmonary disease; FFS, fee-for-service; HMO, health maintenance organizations; ICU, intensive care unit; OR, odds ratio; PDC, proportion of days covered. 


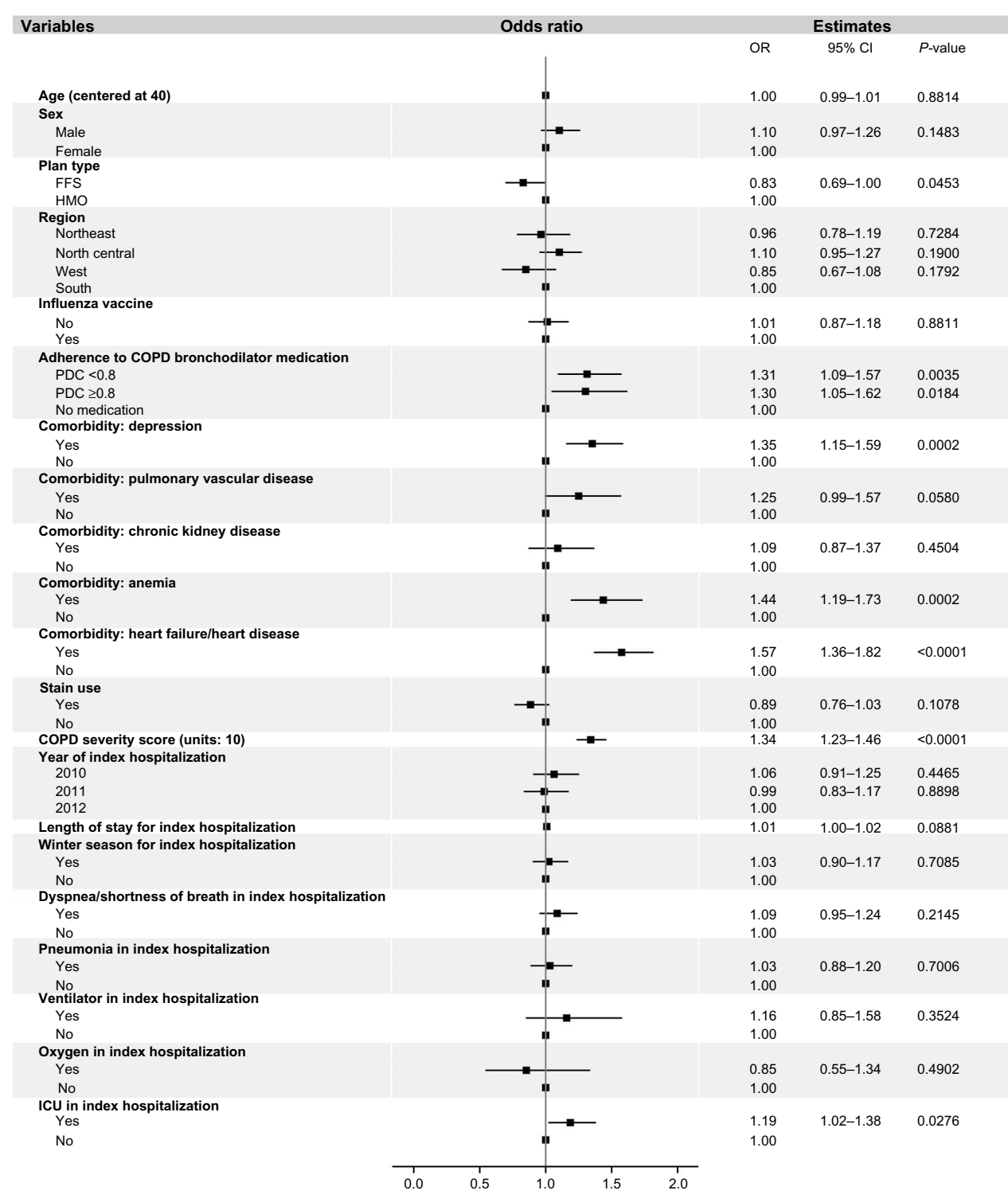

Figure S2 Association between predictors and COPD as any diagnosis 30-day unplanned readmission after an initial COPD-caused hospitalization.

Abbreviations: $\mathrm{Cl}$, confidence interval; COPD, chronic obstructive pulmonary disease; FFS, fee-for-service; HMO, health maintenance organizations; ICU, intensive care unit; OR, odds ratio; PDC, proportion of days covered.

\section{Publish your work in this journal}

ClinicoEconomics \& Outcomes Research is an international, peerreviewed open-access journal focusing on Health Technology Assessment, Pharmacoeconomics and Outcomes Research in the areas of diagnosis, medical devices, and clinical, surgical and pharmacological intervention. The economic impact of health policy and health systems organization also constitute important areas of coverage. The manuscript management system is completely online and includes a very quick and fair peer-review system, which is all easy to use. Visit http://www.dovepress.com/testimonials.php to read real quotes from published authors. 